\section{In Reply: Dismantling the Apocalypse Narrative: The Myth of the COVID-19 Stroke}

To the Editor:

We read "Letter: Dismantling the Apocalypse Narrative: The Myth of the COVID-19 Stroke" ${ }^{1}$ with surprise and disappointment. The letter has major fallacies, misinterpretations, and attributing conclusions not implied by us. ${ }^{2}$ With the prolific and growing literature on COVID-19 and stroke, ${ }^{2-29}$ it is clearly not a myth. We advise the authors to reconsider this fundamental feature of the current pandemic, and we strongly recommend them to get themselves familiar with the cited manuscripts that describe the pathophysiology of cerebrovascular events in COVID-19 patients. ${ }^{3-14,30-40}$ It is a moral imperative in a pandemic for clinicians to raise awareness about associations even when proof of causation is pending.

The authors ${ }^{1}$ repeatedly made subjective false claims characterizing our honest observations as scientifically unfounded, and then themselves add their subjective baseless opinion "that this information exacerbates anxiety among the youth."

It is never one's intent to raise public fear. Instead, it is to promptly increase awareness among the public and healthcare community, mainly that COVID-19 is a new virus, and we do not have a full grasp on its manifestations yet. The disease has been devastating, leading to more than 32 million cases and close to one million casualties. Our responsibility is to promptly report any noteworthy trends and be vocal in the media to reach the most massive audience to spread awareness.

Neurointerventionalists from cities hit hard by the pandemic and working in comprehensive stroke centers were able to identify unusual trends that prompted further investigations, an observation that the senior author $\mathrm{R}$. Rahme may not have experienced at his primary stroke center (SBH health system). Based on the data presented in their table, it seems that they are a low volume primary stroke center suggested by the sole case of LVO during March-April 2018 and 2019. Philadelphia was not hit as hard as New York. However, in early April, we encountered many cases of COVID-19 positive patients that required mechanical thrombectomies in addition to sinus thrombosis. We published numerous papers on our experience, ${ }^{2,25-29,41-45}$ and we implemented a joint effort collaboration with other institutions in the U.S. and outside to better understand this phenomenon.

Only a fraction of patients acquiring COVID-19 are at risk of stroke (1\%-6\%). ${ }^{17,46,47}$ As such, other institutions, that have not experienced a peak in COVID-19 cases, may miss such a trend. Therefore, during a pandemic, it is the duty of healthcare providers practicing in busy centers to raise awareness if they notice anything unusual. Such efforts may push the population to take the disease seriously and follow the guidelines to decrease their risk of getting the disease and its complications. In addition, reporting of such observations allows other healthcare practi- tioners to evaluate this phenomenon in their patient populations. Given the narrow time window of stroke intervention and outcomes being related to early intervention, it is vital to overemphasize stroke symptoms within the community to allow patients to gain from the current therapies.

To help pinpoint and clarify the inaccuracies as presented by the authors, ${ }^{1}$ we provide the following responses to the statements made in their letter:

1- "In fact, during the pandemic, stroke centers, including ours (Table), have experienced significant reductions, rather than increases in the rates of strokes, large vessel occlusions (LVOs), and thrombectomies."

We, and other centers, have experienced a similar phenomenon, ${ }^{25}$ except for the decrease in thrombectomies for large vessel occlusion. Even the data presented in table 1 showed that the numbers of LVOs quadrupled at their hospital. ${ }^{25,48}$ In fact, the reduction in telestroke consults and total stroke admission started before releasing the 2 publications. ${ }^{2,23}$ Patients were delaying presentation to the hospitals due to fear of the contagion. The rationale is that patients with mild and moderate symptoms might delay presentation, where some may improve, and others may worsen and either present to the hospital late or possibly pass away at home. In fact, the Fire Department of the City of New York reported an almost 4-times normal rate of patients being dead on emergency medical service arrival during the pandemic period. ${ }^{48}$ The authors appear to be confusing the quarantine effect on stroke broadly (which has also been well documented) in the literature with the actual scientific pathophysiology of the disease. ${ }^{49,50}$ COVID-19 is been overwhelmingly demonstrated to be pro-thrombotic and causes clots to form in a wide range of organ systems... whether fractures in systems of care, changed referral patterns, ED resource reallocation, social distancing, or self-isolation result in decreased stroke presentation to hospitals, the pro-thrombotic reality of COVID-19 is scientifically unarguable. It belies logic that such a disease would not affect stroke presentation and it is unclear to us why the authors would seek to conflate the broad societal "shut down" with scientific discussion of the disease pathophysiology.

\section{2- "While the authors try to make a similar claim, the vast majority of their patients (12/14) were older than $50 \mathrm{yr}$ and, of the 2 patients younger than 50, 1 had cerebral venous thrombosis."}

Can the authors point where did we claim that our population is younger than $50 \mathrm{yr}$ ? The result section clearly shows the average age of the 14 patients, $60.1 \pm 11.1 \mathrm{yr}$. Second, the discussion mentions that $42 \%$ were 55 yr or younger. Do the authors believe that this is not worthy of sharing? There are now multiple publications from many different geographies that all demonstrate 
COVID-19 positive ELVO populations are statistically younger than non-COVID-19 populations. ${ }^{20,21,41,48,51}$

\section{3- "Overall, the vast majority of their patients (12/14) had cardio- vascular risk factors (8/14)?"}

Does the author mean $12 / 14$ or $8 / 14$ had no cardiovascular risk factors? We mentioned that $42 \%(8 / 14)$ had no traditional risk factors in the result section and discussion. We do not understand what the authors are implying here. Furthermore, statistically significant differences in traditional stroke risk factors have been well demonstrated between COVID-19 ELVO patients and non-COVID-19 ELVO patients. ${ }^{48}$

\section{4- "While 50\% (7/14) had pneumonia andlor adult respiratory distress syndrome, suggesting severe COVID-19."}

This is incorrect and demonstrates that the authors misunderstood our letter. The data presented represents patients without regard for nonspecific terminology, such as severe or mild. In fact, the publications simply point out that COVID-19 puts patients at risk of stroke. Additionally, our data alerts people to the fact that stroke can be the presenting symptom of a COVID-19 infection. The authors should be aware that SARS-CoV-2 positivity has since been demonstrated to be an independent risk factor for imaging confirmed stroke and for ELVO in specific. ${ }^{52,53}$

\section{5- "Most importantly, there was no mention whatsoever of any etiologic stroke workup in those patients."}

Those patients were admitted to a comprehensive stroke center and underwent standard complete stroke workups. By stating that some of the patients did not have any risk factors for stroke, we clearly had to have performed an etiologic stroke workup which did not show any other etiology. Otherwise, we couldn't claim that there were no risk factors for stroke.

\section{6- "Therefore, the suggestion of a causal relationship between} COVID-19 and stroke remains unfounded."

It may be beneficial for the authors to read the conclusion one more time; "Unusual trends have been seen in AIS patients who are COVID-19 positive; while it is too early to establish direct causality, our preliminary data can be used to raise awareness in the population. We are seeing younger patients with no risk factors presenting with AIS and MT procedures are more challenging to deal with. It is crucial in pandemic times to watch and follow closely noteworthy trends and investigate and report new findings."

Currently, there is more than anecdotal evidence linking COVID-19 to stroke. The incidence of stroke in COVID-19 hospitalized patients ranges from $0.9 \%-2 \%,{ }^{17,46,47}$ increasing to $5.7 \%$ in severe disease. ${ }^{17}$ COVID-19 has been reported to be an independent predictor of stroke (OR, 3.9; 95\% CI, 1.7-8.9; P0.001), ${ }^{52}$ and compared to influenza; it has a 7.5-fold higher rate of ischemic stroke. ${ }^{47}$ Moreover, a study by Yaghi et $\mathrm{al}^{51}$ reported a $65.6 \%$ incidence of cryptogenic stroke in COVID19 patients compared to contemporary (30.4\%) and historical controls $(25.0 \%)$. Histological analysis of lung tissue in patients with Covid-19 showed a distinctive severe endothelial injury characterized by widespread thrombosis and microangiopathy. Compared to influenza, COVID-19 patients were nine times more likely to have alveolar microthrombi. ${ }^{54}$ Several recent publications reported a similar experience to Oxley et $\mathrm{al}^{23}$ in terms

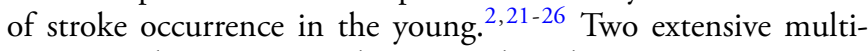
center studies reviewing large vessel occlusion in COVID-19 under review have observed that among a group of patients undergoing a mechanical thrombectomy, $19 \%$ were under $50 \mathrm{yr}$, and $34 \%$ under 55 ( 12 centers from the USA and Europe). Moreover, a recent comparative analysis depicting the experience from New York corroborated such early findings. ${ }^{48}$

Finally, we appreciate the dialogue as this is necessary for advancement of science and better care for our patient populations but we stand by the integrity, value and importance of the data we shared. We believe that raising awareness about an association between the COVID-19 pandemic and stroke is not only beneficial for the population and practitioners but it is a moral imperative. We respectfully disagree with Dr Rahme and coauthors $^{1}$ and invite them to be more precise and scientific in their criticism and to join us in raising awareness about the association of stroke and COVID-19.

\section{Funding}

This study did not receive any funding or financial support.

\section{Disclosures}

Dr Jabbour is a consultant for Medtronic and MicroVention. Dr Tjoumakaris is a consultant for Stryker. The other authors have no personal, financial, or institutional interest in any of the drugs, materials, or devices described in this article. 
₹Department of Radiology Mayo Clinic

Rochester, Minnesota

${ }^{S}$ Department of Neurosurgery

Good Samaritan Hospital Medical Center

West Islip, New York

${ }^{5}$ Department of Neurosurgery

The Ohio State University Wexner Medical Center

Columbus, Ohio

"Department of Neurosurgery

Advocate Aurora Health

Chicago, Illinois

${ }^{\#}$ Department of Neuroscience

Valley Baptist Medical Center/University of Texas Rio Grande Valley

Harlingen, Texas

** Department of Neurosurgery

University of Michigan

Ann Arbor, Michigan

\#Department of Neurosurgery

Duke University Medical Center

Durham, North Carolina

${ }^{S S}$ Department of Neurosurgery and Toshiba Stroke Research Center School of Medicine and Biomedical Sciences

University at Buffalo

State University of New York

Buffalo, New York

"Department of Neurosurgery

University of Iowa Hospital and Clinics

Iowa City, Iowa

IIII Department of Neurosurgery and Radiology

Columbia University Medical Center

New York, New York

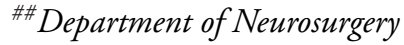

Mayo Clinic

Scottsdale, Arizona

\section{REFERENCES}

1. Miller A, Segan S, Rehmani R, Shabsigh R, Rahme R. Letter: dismantling the apocalypse narrative: the myth of the COVID-19 stroke. Neurosurgery. published online: September 5, 2020 (doi:10.1093/neuros/nyaa419).

2. Sweid A, Hammoud B, Weinberg JH, et al. Letter: thrombotic neurovascular disease in COVID-19 patients. Neurosurgery. 2020;87(3):E400-E406.

3. Mishra AK, Sahu KK, Lal A, Sargent J. Mechanisms of stroke and the role of anticoagulants in COVID-19. J Formos Med Assoc. 2020;119(11):1721-1722.

4. Giraudon P, Bernard A. Inflammation in neuroviral diseases. J Neural Transm. 2010;117(8):899-906.

5. Varga Z, Flammer AJ, Steiger P, et al. Endothelial cell infection and endotheliitis in COVID-19. Lancet North Am Ed. 2020;395(10234):1417-1418.

6. Barnes BJ, Adrover JM, Baxter-Stoltzfus A, et al. Targeting potential drivers of COVID-19: neutrophil extracellular traps. J Exp Med. 2020;217(6):e20200652.

7. Lorenzo C, Francesca B, Francesco P, Elena C, Luca S, Paolo S. Acute pulmonary embolism in COVID-19 related hypercoagulability. published online: May 30, 2020. J Thromb Thrombolysis. (doi:10.1007/s11239-020-02160-1).

8. Han H, Yang L, Liu R, et al. Prominent changes in blood coagulation of patients with SARS-CoV-2 infection. Clin Chem Lab Med. 2020;58(7):1116-1120.

9. Tang N, Bai H, Chen X, Gong J, Li D, Sun Z. Anticoagulant treatment is associated with decreased mortality in severe coronavirus disease 2019 patients with coagulopathy. J Thromb Haemost. 2020;18(5):1094-1099.
10. Campbell CM, Kahwash R. Will complement inhibition be the new target in treating COVID-19-Related systemic thrombosis? Circulation. 2020;141(22):1739-1741.

11. Tang N, Li D, Wang X, Sun Z. Abnormal coagulation parameters are associated with poor prognosis in patients with novel coronavirus pneumonia. $J$ Thromb Haemost. 2020;18(4):844-847.

12. Zhang Y, Xiao M, Zhang S, et al. Coagulopathy and antiphospholipid antibodies in patients with Covid-19. N Engl J Med. 2020;382(17):e38.

13. Wang J, Hajizadeh N, Moore EE, et al. Tissue plasminogen activator (tPA) treatment for COVID-19 associated acute respiratory distress syndrome (ARDS): a case series. J Thromb Haemost. 2020;18(7):1752-1755.

14. Feldstein LR, Rose EB, Horwitz SM, et al. Multisystem inflammatory syndrome in U.S. children and adolescents. N Engl J Med. 2020;383(4):334-346.

15. Klok FA, Kruip M, van der Meer NJM, et al. Confirmation of the high cumulative incidence of thrombotic complications in critically ill ICU patients with COVID19: an updated analysis. Thromb Res. 2020;191:148-150.

16. Foley JH, Conway EM. Cross talk pathways between coagulation and inflammation. Circ Res. 2016;118(9):1392-1408.

17. Mao L, Jin H, Wang M, et al. Neurologic manifestations of hospitalized patients with coronavirus disease 2019 in Wuhan, China. JAMA Neurol. 2020;77(6):683690.

18. Tan CW, Cheen MHH, Wong WH, et al. Elevated activated partial thromboplastin time-based clot waveform analysis markers have strong positive association with acute venous thromboembolism. Biochem Med (Zagreb). 2019;29(2):020710.

19. Paterson RW, Brown RL, Benjamin L, et al. The emerging spectrum of COVID-19 neurology: clinical, radiological and laboratory findings. Brain 2020;143(10):3104-3120

20. Escalard S, Maïer B, Redjem H, et al. Treatment of acute ischemic stroke due to large vessel occlusion with COVID-19. Stroke. 2020;51(8):2540-2543.

21. Wang A, Mandigo GK, Yim PD, Meyers PM, Lavine SD. Stroke and mechanical thrombectomy in patients with COVID-19: technical observations and patient characteristics. J NeuroIntervent Surg. 2020;12(7):648-653.

22. Cavallieri F, Marti A, Fasano A, et al. Prothrombotic state induced by COVID-19 infection as trigger for stroke in young patients: a dangerous association. eNeurologicalSci. 2020;20:100247.

23. Oxley TJ, Mocco J, Majidi S, et al. Large-Vessel stroke as a presenting feature of covid-19 in the young. $N$ Engl J Med. 2020;382(20):e60.

24. Gunasekaran K, Amoah K, Rajasurya V, Buscher MG. Stroke in a young COVID19 patient. QJM 2020;113(8):573-574.

25. Sweid A, Jabbour P, Tjoumakaris S. Letter to the editor: incidence of acute ischemic stroke and rate of mechanical thrombectomy during the COVID-19 pandemic in a large tertiary care telemedicine network. World Neurosurg. 2020;140: 491-492.

26. Sweid A, Hammoud B, Bekelis K, et al. Cerebral ischemic and hemorrhagic complications of coronavirus disease 2019. Int J Stroke. 2020;15(7):733-742.

27. Hoelscher C, Sweid A, Ghosh R, et al. Cerebral deep venous thrombosis and COVID-19: case report. J Neurosurg. 2020:1-4.

28. Al Kasab S, Almallouhi E, Alawieh A, et al. International experience of mechanical thrombectomy during the COVID-19 pandemic: insights from STAR and ENRG. J NeuroIntervent Surg. 2020;12(11):1039-1044.

29. Jabbour P, Sweid A, Tjoumakaris $S$, et al. In reply: may cooler heads prevail during a pandemic: stroke in COVID-19 patients or COVID-19 in stroke patients? Neurosurgery. published online: 2020 (doi:10.1093/neuros/nyaa385).

30. Alawieh AM, Spiotta AM. Letter: may cooler heads prevail during a pandemic: stroke in COVID-19 patients or COVID-19 in stroke patients? Neurosurgery. 2020;87(4):E522.

31. Imai $Y$, Kuba K, Rao $S$, et al. Angiotensin-converting enzyme 2 protects from severe acute lung failure. Nature. 2005;436(7047):112-116.

32. Kuba K, Imai $Y$, Rao $S$, et al. A crucial role of angiotensin converting enzyme 2 (ACE2) in SARS coronavirus-induced lung injury. Nat Med. 2005;11(8):875-879.

33. Lopez Verrilli MA, Pirola CJ, Pascual MM, Dominici FP, Turyn D, Gironacci MM. Angiotensin-(1-7) through AT 2 receptors mediates tyrosine hydroxylase degradation via the ubiquitin-proteasome pathway. $J$ Neurochem. 2009;109(2):326-335.

34. Turner AJ, Hiscox JA, Hooper NM. ACE2: from vasopeptidase to SARS virus receptor. Trends Pharmacol Sci. 2004;25(6):291-294.

35. Sampaio WO, Nascimento AAS, Santos RAS. Systemic and regional hemodynamic effects of angiotensin-(1-7) in rats. Am J Physiol Heart Circ Physiol. 2003;284(6):H1985-H1994. 
36. Mecca AP, Regenhardt RW, O'Connor TE, et al. Cerebroprotection by angiotensin-(1-7) in endothelin-1-induced ischaemic stroke. Exp Physiol. 2011;96(10):1084-1096.

37. Campagnole-Santos MJ, Diz DI, Santos RA, Khosla MC, Brosnihan KB, Ferrario CM. Cardiovascular effects of angiotensin-(1-7) injected into the dorsal medulla of rats. Am J Physiol. 1989;257(1 Pt 2):H324-H329.

38. Xu P, Sriramula S, Lazartigues E. ACE2/ANG-(1-7)/Mas pathway in the brain: the axis of good. Am J Physiol Regul Integr Comp Physiol. 2011;300(4):R804-R817.

39. Chen J, Xiao X, Chen S, et al. Angiotensin-converting enzyme 2 priming enhances the function of endothelial progenitor cells and their therapeutic efficacy. Hypertension. 2013;61(3):681-689.

40. Chen J, Zhao Y, Chen S, et al. Neuronal over-expression of ACE2 protects brain from ischemia-induced damage. Neuropharmacology. 2014;79:550-558.

41. Ntaios G, Michel P, Georgiopoulos G, et al. Characteristics and outcomes in patients with COVID-19 and acute ischemic stroke: the global COVID-19 stroke registry. Stroke. 2020;51(9):e254-e258.

42. Bhaskar S, Sharma D, Walker AH, et al. Acute neurological care in the COVID19 era: the pandemic health system REsilience PROGRAM (REPROGRAM) consortium pathway. Front Neurol. 2020;11:579.

43. Mouchtouris N, Lavergne P, Montenegro TS, et al. Telemedicine in neurosurgery: lessons learned and transformation of care during the COVID-19 pandemic. World Neurosurg. 2020;140:e387-e394.

44. Pandey AS, Ringer AJ, Rai AT, et al. Minimizing SARS-CoV-2 exposure when performing surgical interventions during the COVID-19 pandemic. J NeuroIntervent Surg. 2020;12(7):643-647.

45. Theofanis TN, Khanna O, Stefanelli A, et al. Letter: Neurosurgery Residency in the COVID-19 era: experiences and insights from Thomas Jefferson University Hospital, Philadelphia, Pennsylvania. Neurosurgery. 2020;87(2): E249.
46. Yaghi S, Ishida K, Torres J, et al. SARS-CoV-2 and stroke in a New York Healthcare System. Stroke. 2020;51(7):2002-2011.

47. Merkler AE, Parikh NS, Mir S, et al. Risk of ischemic stroke in patients with coronavirus disease 2019 (COVID-19) vs patients with influenza. JAMA Neurol. 2020;77(11):1-7.

48. Majidi S, Fifi JT, Ladner TR, et al. Emergent large vessel occlusion stroke during New York City's COVID-19 outbreak. Stroke. 2020;51(9):2656-2663.

49. Siegler JE, Cardona P, Arenillas JF, et al. Cerebrovascular events and outcomes in hospitalized patients with COVID-19: the SVIN COVID-19 multinational registry. published online: 2020. Int J Stroke. (doi:10.1177/1747493020959216).

50. Kansagra AP, Goyal MS, Hamilton S, Albers GW. Collateral effect of COVID-19 on stroke evaluation in the United States. N Engl J Med. 2020;383(4):400-401.

51. Yaghi S, Ishida K, Torres J, et al. SARS2-CoV-2 and stroke in a New York healthcare system. published online: 2020. Stroke. (doi:10.1161/STROKEAHA. 120.030335).

52. Belani P, Schefflein J, Kihira S, et al. COVID-19 is an independent risk factor for acute ischemic stroke. AJNR Am J Neuroradiol. 2020;41(8):1361-1364.

53. Kihira S, Schefflein J, Mahmoudi K, et al. Association of coronavirus disease (COVID-19) with large vessel occlusion strokes: a case-control study. Am J Roentgenol. 2020:1-6.

54. Ackermann M, Verleden SE, Kuehnel M, et al. Pulmonary vascular endothelialitis, thrombosis, and angiogenesis in COVID-19. NEngl JMed. 2020;383(2):120-128.

(c) Congress of Neurological Surgeons 2020. All rights reserved. For permissions, please e-mail: journals.permissions@oup.com

$10.1093 /$ neuros/nyaa522 